\title{
Actions, not words, by 2007
}

\section{Berkeley}

Declaring a state of emergency in science reminiscent of the days of Sputnik, a group of some 250 notables met here last week at the urging of Energy Secretary James Watkins and Nobel laureate Glenn Seaborg to find ways of improving the much-lamented state of mathematics and science education in the United States.

Among the actions called for were a mobilization of the country's many national laboratories, a nationwide teacher training programme and even a musical video to elevate mathematics and science in the minds of American elementary and high school students.

The Maths/Science Education Action Conference, convened at the Lawrence Hall of Science (LHS) in Berkeley from 9 to 11 October, was attended by representatives from education, industry, the National Science Foundation and a host of other government agencies. Its purpose was to identify specific programmes the government can adopt to reverse a steady decline in science and mathematics education.

This decline, demonstrated in several recent studies that show US students lagging behind their counterparts in many developed countries, is widely seen as threatening the technological edge of the United States. "No more talking . . . no more crying about the problem", proclaimed co-host and LHS director Marjorie Gardner. "Let's get on to the solutions. Science is a core subject, not an elective. Science is for everyone."

Despite such an admonishment, the conference was not wholly free of traditional platitudinizing - some speakers espoused such vacuous goals as making US mathematics and science students the best in the world. Nevertheless, some specific recommendations did emerge, which addressed seven areas of concern: teachers; curriculum; underrepresented students; the science student pipeline; inner-city/ rural schools; national maths/science literacy; community involvement and professional involvement.

A final report is not yet available, but a draft summarizing the working group proposals argued for the development, within a year, of a streamlined process for awarding credentials to prospective teachers and a four-week training programme to reach ten per cent of existing mathematics and science teachers.

One of the conference's chief goals was to find ways to reach women and inner city and minority youth, who are traditionally underrepresented in science. It was hoped that, by establishing programmes at various national laboratories, the Department of Energy (DoE) would serve as a model for other federal agencies to help revita- lize science education in targeted districts. To that end, Watkins stopped at the Fermi National Accelerator Laboratory outside Chicago, on the way to the conference, to break ground for a $\$ 1.2$ million science education centre. And Watkins told the conference that he expected to have 20 national laboratories starting similar activities within the year.

A working group chaired by Bob Goodwin, executive director of the White House Initiative on Historically Black Colleges \& Universities, suggested that this effort could be expanded by bringing in private industry, colleges and state and local governments to help reach underrepresented students. The group proposed identifying ten school districts, and initiating programmes at half of them within the year. Another group suggested the music video as a way to reach those students usually left out of science and mathematics culture.

The draft summary urged the President's science adviser to establish and chair an interagency committee that would extend the DoE model by developing partnerships with other government agencies. This body would then work with the National Science Foundation (NSF) and the Department of Education on a national mathematics and science curriculum. The science adviser was also asked to establish alliances between the government and ten per cent of the country's school districts in the next year.
Those present clearly appreciated that a cabinet member had taken time to be the host of such a meeting: Watkins received a standing ovation near the end of the tiring final day. For his part, Watkins praised the reports of the working groups, saying that the bulk of them was "so much better than what we have, that we have to get a document out". Watkins also assured the meeting that its suggestions would be incorporated into DOE's National Energy Strategy, a draft of which is to be submitted to President Bush on 1 April 1990.

Although many of these ideas are aimed at producing short-term benefits, the goal of the conference was to enable the class of 2007 (children born this year) to acquire the knowledge necessary to build the country's technical and scientific base. This date is symbolic because it marks the 50th anniversary of the launching of the Soviet satellite Sputnik, an event important to conference organizers.

"We're facing many of the same problems in science and mathematics education that we faced then", said Seaborg, citing poor teacher training, an outmoded curriculum and general public illiteracy on science issues.

To put into practice the meeting's broad proposals will mean reorganizing and refocusing the already substantial resources committed to science and mathematics education, said Watkins. It will also, he admitted, take more money. "Will I have a fight? Probably. Will I get it? Yes - because I'll go and gripe to the President and he'll support me."

Robert Buderl

\section{BTG looks towards Europe}

\section{London}

THE British Technology Group (BTG), Britain's still-public technology transfer organization, is to spread its sphere of activity into mainland Europe. The group subsumes the activities of the National Research Development Corporation originally formed to patent and license the intellectual property rights (IPR) to scientific and technological discoveries made by academic researchers.

BTG has been asked by the European Institute of Technology (EIT), an international consortium supported by IBM Europe, AT\&T, Glaxo, Enichem and Kodak, to deal also with innovations arising from the scientific programmes it supports at European universities. John Morton, company secretary of BTG, said EIT had recognized BTG's position as "market leader in IPR management".

EIT's objective is to stimulate cooperation between industry and universities by sponsoring research. In its first year it received nearly 1,000 research proposals, of which it supported 35 , with funds ranging from 10,000 to 15,000 ECUs (1 European Currency Unit $=£ 0.69$ ). In phase II of the 1989 programme, nine projects will be selected, and will receive up to 750,000 ECUs each. BTG will be responsible for all the patenting and licensing of any technology in which the member companies of EIT decide they are not interested. Among other things, it will fall to BTG to decide how academics should be rewarded for their work.

Historically BTG has worked almost exclusively on British inventions, but it has lately realized that many overseas companies may have portfolios with under-developed inventions which BTG's expertise in technology and intellectual property protection skills could turn into money-spinners. BTG has strong links with the United States, and recent deals have established a firm base in Japan. The move onto the European mainland is the next stage of BTG's international expansion, and BTG has identified medium and small European enterprises as a potential growth area.

NATURE · VOL $341 \cdot 19$ OCTOBER 1989 